\title{
Commentary Death to sepsis: targeting apoptosis pathways in sepsis
} Derek S Wheeler ${ }^{1,2,3}$

\author{
${ }^{1}$ Pediatric Intensive Care Unit, Division of Critical Care Medicine, Cincinnati Children's Hospital Medical Center, 3333 Burnet Avenue, Cincinnati, \\ $\mathrm{OH}$ 45229-3039, USA \\ ${ }^{2}$ The Kindervelt Laboratory for Critical Care Medicine Research, Cincinnati Children's Research Foundation, 3333 Burnet Avenue, Cincinnati, \\ $\mathrm{OH}$ 45229-3039, USA \\ ${ }^{3}$ Department of Pediatrics, University of Cincinnati College of Medicine, 3333 Burnet Avenue, Cincinnati, OH 45229-3039, USA
}

Corresponding author: Derek S Wheeler, Derek.wheeler@cchmc.org

Published: 7 December 2009

Critical Care 2009, 13:1010 (doi:10.1186/cc8162)

This article is online at http://ccforum.com/content/13/6/1010

(c) 2009 BioMed Central Ltd

See related research by Weber et al., http://ccforum.com/content/13/5/R146

\begin{abstract}
Sepsis is a significant public health problem and is one of the leading causes of death in critically ill patients admitted to the intensive care unit. The cost, both in terms of lives lost and annual healthcare expenditures, from sepsis is staggering. Unfortunately, despite an increasing understanding of the unique molecular pathobiology of sepsis, mortality has remained more or less stable over the past decade. Moreover, promising therapies in preclinical models of sepsis have universally failed to live up to initial expectations in subsequent clinical trials. Multiple studies have demonstrated that apoptosis plays a major role in the pathobiology of sepsis and acute lung injury, making the apoptosis pathway an attractive target for therapy. Herein, the role of apoptosis in sepsis is briefly discussed, highlighting studies with one potential therapeutic agent targeting the apoptosis pathway.
\end{abstract}

Weber and colleagues recently demonstrated that the broad caspase inhibitor VX-166 significantly inhibited lymphocyte apoptosis and improved survival in two complementary rodent models of sepsis - endotoxin shock, and cecal ligation and puncture [1]. Sepsis remains a significant worldwide public health problem and is currently the 10th leading cause of death overall in the United States - there are now more deaths attributable to sepsis than to coronary artery disease, stroke, or cancer [2]. There are approximately 750,000 cases of severe sepsis per year in the United States alone, and the incidence of sepsis is expected to further increase by $1.5 \%$ every year, resulting in an additional 1 million cases per year by 2020 [2-4]. The financial toll attributed to sepsis is staggering - the most recent statistics suggest that sepsis accounts for nearly $\$ 17$ billion and $€ 5.8-7.6$ billion in annual healthcare expenditures in the United States and in Europe, respectively $[2,4,5]$. Sepsis also remains a significant health problem in children, accounting for nearly 4,500 pediatric deaths in the United States every year and close to $\$ 2$ billion per year in annual healthcare expenditures [6]. These statistics do not take into account the additional hidden costs attributed to the loss of productivity related to years of life lost for both critically ill children and adults who succumb to sepsis. Based on these sobering statistics, there is great interest in identifying novel treatments for managing critically ill children and adults with sepsis.

Unfortunately, promising therapies in preclinical models of sepsis have universally failed to live up to initial expectations in subsequent clinical trials [7]. As a matter of record, to date there have been only two positive clinical trials in critically ill adults with sepsis - early goal-directed therapy [8], and activated protein $\mathrm{C}$ (drotrecogin alfa, Xigris ${ }^{\circledR}$; Eli Lilly and Co., Indianapolis, IN, USA) [9]. Two additional therapies - adrenal corticosteroids $[10,11]$ and intravenous immunoglobulins [12] - have shown promise, although the results on mortality reduction have been inconsistent. As a result, the search for novel therapeutic targets for the management of critically ill patients with sepsis continues - one potential novel pharmacologic approach to therapy involves targeting the apoptosis pathway. Of interest, at least one proposed mechanism for activated protein $\mathrm{C}$ involves inhibition of the apoptosis pathway [13].

The Greek word apoptosis literally refers to the dropping off of petals or leaves from plants or trees. Apoptosis was first used to describe an energy-dependent form of programmed cell death or cell suicide in 1972 by Kerr and colleagues [14]. The importance of apoptosis in the regulation of growth and development as well as the maintenance of cellular homeostasis is now widely appreciated [15]. Apoptosis is characterized morphologically by cell membrane blebbing, cell shrinkage, chromatin condensation, and DNA fragmen-

$\mathrm{IL}=$ interleukin; $\mathrm{TNF}=$ tumor necrosis factor. 
tation. As cells undergo apoptosis, they are phagocytosed by surrounding macrophages before membrane rupture, thereby preventing the inflammatory response that occurs via the release of cell contents by cells undergoing necrotic death.

Apoptosis is classically triggered via two signaling pathways, the intrinsic pathway (also known as the mitochondrial pathway) and the extrinsic pathway (also known as the death receptor pathway). The extrinsic pathway is triggered when death ligands (for example, FasL, TNF $\alpha$, AproL, and TRAIL) bind to their respective cell surface death receptors (Fas, TNFR1, DR3, DR4, and DR5). Ligand binding results in the recruitment of several adapter proteins and the subsequent association and activation of the initiator caspases (cysteine aspartyl-specific proteases). The caspases are a family of cell proteases that exist as zymogens within cells and can be activated by either autocatalytic activation or other proteases. The initiator caspases (primarily caspase 8 and caspase 10) subsequently activate the effector caspases (primarily caspase 3 , caspase 6 , and caspase 7). Alternatively, the intrinsic pathway is triggered by intracellular stress, which leads to mitochondrial outer membrane permeabilization and release of mitochondrial proteins, such as cytochrome c. Cytochrome c forms a complex with apoptosis activating factor 1 and the initiator caspase 9, called the apoptosome. Caspase 3 is recruited and then activated by the apoptosome, at which point these two pathways converge. In addition, there is additional cross-talk between the two pathways.

The entire process of apoptosis is highly regulated by both pro-apoptopic and anti-apoptotic factors [15-17]. The effector caspases execute the apoptosis program by cleaving other cellular proteins crucial for cell survival [15].

Multiple studies have now demonstrated that apoptosis plays a major role in the pathobiology of sepsis. For example, there is extensive evidence for apoptosis of lymphocytes and gastrointestinal epithelial cells during sepsis $[16,18]$. In addition, apoptosis of both alveolar epithelial cells and respiratory endothelial cells has been conclusively demonstrated in animals and humans with acute lung injury and the acute respiratory distress syndrome [17]. More importantly, the evidence from several animal models strongly suggests that inhibition of apoptosis in both sepsis and acute lung injury/ acute respiratory distress syndrome improves survival $[17,18]$.

In the current study, Weber and colleagues demonstrated that the small-molecule, broad caspase inhibitor VX-166 inhibited both lymphocyte and endothelial cell apoptosis in vivo and inhibited lipopolysaccharide-mediated $\mathrm{IL}-1 \beta$ and IL-18 release from peripheral blood monocytes [1]. The effects of VX-166 were then tested in two complementary rodent models of sepsis - namely, endotoxin shock and cecal ligation and puncture. VX-166 was administered by either repeat intravenous bolus or by an implanted mini-osmotic pump. VX-166 significantly improved survival in both models, even when administered up to 8 hours following the onset of sepsis [1]. Additional mechanistic data were provided, showing that VX-166 prevented lymphocyte apoptosis in vivo and decreased circulating levels of endotoxin and proinflammatory cytokines in both models.

While these studies are preliminary in nature, the fact that VX-166 improved survival even when administered well after the onset of sepsis (a much more clinically relevant model) is certainly intriguing and provides supportive evidence that targeting the apoptosis pathway may represent a novel approach to the management of sepsis in the clinical setting. Future studies are likely to further elucidate the role of caspase inhibitors such as VX-166 in critically ill patients with sepsis.

\section{Competing interests}

The author declares that they have no competing interests.

\section{Acknowledgement}

The present work was supported by the National Institutes of Health, 5KO8GM077432 and 1R03HD058246.

\section{References}

1. Weber $\mathrm{P}$, Wang $\mathrm{P}$, Maddens $\mathrm{S}$, Wang PSH, Wu R, Miksa M, Dong W, Mortimore M, Golec JMC, Charlton P: VX-166: a novel potent small molecule caspase inhibitor as a potential therapy for sepsis. Crit Care 2009, 13:R146.

2. Angus DC, Linde-Zwirble WT, Lidicker J, Clermont G, Carcillo J, Pinsky MR: Epidemiology of severe sepsis in the United States: analysis of incidence, outcome, and associated costs of care. Crit Care Med 2001, 29:1303-1310.

3. Dombrovskiy VY, Martin AA, Sunderram J, Paz HL: Rapid increase in hospitalization and mortality rates for severe sepsis in the United States: a trend analysis from 1993 to 2003. Crit Care Med 2007, 35:1244-1250.

4. Martin GS, Mannino DM, Eaton S, Moss M: The epidemiology of sepsis in the United States from 1979 through 2000. N Engl J Med 2003, 348:1546-1554.

5. Murch O, Collin M, Hinds CJ, Thiemermann C: Lipoproteins in inflammation and sepsis. I. Basic science. Intensive Care Med 2007, 33:13-24.

6. Watson RS, Carcillo JA, Linde-Zwirble WT, Clermont G, Lidicker J, Angus DC: The epidemiology of severe sepsis in children in the United States. Am J Respir Crit Care Med 2003, 167:695701.

7. Wheeler DS, Zingarelli B, Wheeler WJ, Wong HR: Novel pharmacologic approaches to the management of sepsis: targeting the host inflammatory response. Recent Pat Inflamm Allergy Drug Discov 2009, 3:96-112.

8. Rivers E, Nguyen B, Havstad S, Ressler J, Muzzin A, Knoblich B, Peterson E, Tomlanovich M: Early goal-directed therapy in the treatment of severe sepsis and septic shock. N Engl J Med 2001, 345:1368-1377.

9. Bernard G, Vincent JL, Laterre PF, LaRosa SP, Dhainaut JF, Lopez-Rodriguez A, Steingrub JS, Garber GE, Helterbrand JD, Ely EW, Fisher CJ Jr, Recombinant human protein C Worldwide Evaluation in Severe Sepsis (PROWESS) study group: Efficacy and safety of recombinant human activated protein $\mathbf{C}$ for severe sepsis. N Engl J Med 2001, 344:699-709.

10. Annane D, Sebille V, Charpentier C, Bollaert PE, Francois B, Korach JM, Capellier G, Cohen Y, Azoulay E, Troche G, ChaumetRiffaud $P$, Bellisant $E$ : Effect of treatment with low doses of hydrocortisone and fludrocortisone on mortality in patients with septic shock. JAMA 2002, 288:862-871.

11. Sprung CL, Annane D, Keh D, Moreno R, Singer M, Freivogel $K$ Weiss YG, Benbenishty J, Kalenka A, Forst H, Laterre PF, Reinhart K, Cuthbertson BH, Payen D, Briegel J, CORTICUS Study 
Group: Hydrocortisone therapy for patients with septic shock. N Engl J Med 2008, 358:111-124.

12. Laupland KB, Kirkpatrick AW, Delaney A: Polyclonal intravenous immunoglobulin for the treatment of severe sepsis and septic shock in critically ill adults: a systematic review and metaanalysis. Crit Care Med 2007, 35:2686-2692.

13. Wesche-Soldato DE, Swan RZ, Chung CS, Ayala A: The apoptotic pathway as a therapeutic target in sepsis. Curr Drug Targets 2007, 8:493-500.

14. Kerr JF, Wyllie AH, Currie AR: Apoptosis: a basic biological phenomenon with wide-ranging implications in tissue kinetics. Br J Cancer 1972, 26:239-257.

15. Jin Z, El-Deiry WS: Overview of cell death signaling pathways. Cancer Biol Ther 2005, 4:139-163.

16. Hotchkiss RS, Nicholson DW: Apoptosis and caspases regulate death and inflammation in sepsis. Nat Rev Immunol 2006, 6:813-822.

17. Tang PS, Mura M, Seth R, Liu M: Acute lung injury and cell death: how many ways can cells die? Am J Physiol Lung Cell Mol Physiol 2008, 294:L632-L641.

18. Hotchkiss RS, Coopersmith CM, Karl IE: Prevention of lymphocyte apoptosis - a potential treatment of sepsis? Clin Infect Dis 2005, 41:S465-S469. 